\title{
KNOWLEDGE AND PREVENTIVE PRACTICE REGARDING HEPATITIS B AMONG THE NURSES IN DHAKA MEDICAL COLLEGE HOSPITAL
}

\begin{abstract}
KHAN NR ${ }^{1}$, RIYA $^{2}$, ISLAM MS ${ }^{3}$, MAJEED HA ${ }^{4}$
Abstract

This was a descriptive cross-sectional study conducted with an aim to assess the level of knowledge and preventive practice regarding hepatitis $B$ among the nurses in Dhaka Medical College Hospital. The study was conducted from January 2015 to June 2015. Total sample was 207 and purposive sampling technique was followed for data collection, which was done by face to face interview. The data were collected on a structured questionnaire and analyzed by SPSS. Out of 207 respondents, majority (54.1\%) were found in the age group of 18 to 30 years, where mean age was $33+0.2$ years. Among them female (83.5\%) outnumbered the male (16.4\%). Most of them (81.2\%) were Muslim. Majority (49.8\%) were educated up to HSC level and half of them (51.7\%) were married. Majority(45.4\%) had family income $>20,000$ taka. Most of them (91.8\%) had good knowledge that virus was the causative agent of hepatitis $B$ and $84.5 \%$ understood 'infected blood transfusion' as common means of disease transmission. About $83.1 \%$ had the knowledge about other routes of transmission. Nearly half $(51.7 \%)$ were not aware of being at risk of infected by $H B V$ but more than half (56.5\%) received vaccination for HBV. Most of them (85\%) stated that hepatitis B had complications. Mean knowledge score was $8.28+2.9$, while $80.7 \%$ had good level of knowledge, only $19.3 \%$ had poor knowledge. Again, mean preventive practice score was $4.78+1.3$, while $87.4 \%$ had good level of preventive practice and $12.6 \%$ had poor preventive practice. Here mean practice of prevention was significantly associated with level of knowledge of respondents $(P<0.001)$. In the study overall knowledge and practice was found to be satisfactory. Most of the nursing staffs were at risk of hepatitis $B$. So appropriate educational and health promotion programs can increase these knowledge \& practice further.
\end{abstract}

Key words: Knowledge and practice regarding hepatitis $B$, occupational safety of nursing staffs.

J Dhaka Med Coll. 2017; 26(1) : 36-42

\section{Introduction}

Hepatitis B virus is a member of Hepadna virus family. It is a DNA virus surrounded by an envelope which contains HBsAg surface antigen which is important for laboratory diagnosis and immunization. In addition to HBsAg, there are two other important antigens: Core antigen ( $\mathrm{HBcAg}$ ) and e antigen (HBeAg). $\mathrm{HBsAg}$ is an indicator of transmissibility. All persons who are HBsAg positive are potentially infectious ${ }^{1}$.The incubation period of HBV infection averages 60-90 days, with a range of 45-160 days. HBV can remain infectious at ambient temperatures in the environment for one week or longer ${ }^{2}$.

HBV is transmitted through blood or body fluids, including wound exudates, semen, vaginal secretions, and saliva. Blood and serum contain the highest concentrations of the virus; saliva contains the lowest. Some examples of parenteral exposures are: needle sticks, sharing or reusing non-sterile needles or syringes, transfusion of blood and blood products, hemodialysis, and tattooing. The most common permucosal exposures are through perinatal transmission from an infected

1. Dr. Nirmeen Rifat Khan, Associate Professor, Department of Community Medicine, Dhaka Medical College, Dhaka.

2. Dr. Sayeda Riya, Associate Professor, Department of Community Medicine, Tairunnessa Memorial Medical College, Gazipur, Dhaka.

3. Dr. Mohammad Shohidul Islam, Lecturer, Community Medicine, Dhaka Medical College, Dhaka.

4. Dr. Hisham Abdul Majeed, Final Year $\left(5^{\text {th }}\right)$ student, Dhaka Medical College, Dhaka.

Correspondence : Dr. Nirmeen Rifat Khan, Associate Professor, Department of Community Medicine, Dhaka Medical College, Dhaka.

Received: 17 January 2017

Accepted: 01 March 2017 
mother to her infant at birth (vertical transmission) and sexual (heterosexual and homosexual) activity (horizontal transmission). Infection with HBV may result in acute or chronic disease, both of which can be asymptomatic. If symptoms are present, onset of acute disease is usually insidious, with loss of appetite, vague abdominal discomfort, nausea, vomiting, and sometimes arthralgia and rash, often progressing to jaundice. Fever may be absent or low-grade. Liver enzyme levels are markedly elevated. Severity of the disease ranges from unapparent cases (detectable only by liver function tests) to fulminant, fatal disease.

HBV infection occurs all over the world. More than one-third of the world's population has been infected with $\mathrm{HBV}^{2}$. An estimated 240 million people are chronically infected with hepatitis B (defined as hepatitis B surface antigen positive for at least 6 months). Approximately 780000 persons die each year from hepatitis B infection; 650000 from cirrhosis and liver cancer due to chronic hepatitis B infection and another 130000 from acute hepatitis ${ }^{3}$. In addition, approximately 4.5 million new HBV infections occur worldwide each year, of which a quarter progresses to liver disease ${ }^{4}$.Worldwide, HBV is a major cause of chronic liver disease and liver cancer ${ }^{2}$.

In low endemic regions, like the United States, Northern Europe, Australia and parts of South America, HBsAg prevalence is less than $2 \%$ and less than $20 \%$ of the population are infected with HBV ${ }^{4}$. In high endemic areas, like Central Asian republics, Southeast Asia, Sub Saharan Africa and the Amazon basin, the HBV carrier rate is 8 to $20 \%$. In some of these areas about 70 to $90 \%$ of them becomes infected with HBV before the age of $40{ }^{5}$. Bangladesh belongs to the intermediate prevalence region for $\mathrm{HBV}$ infection. Hepatitis B surface antigen (HBsAg) prevalence ranges from $3-7 \%$ among the general population and $1.5-12 \%$ among children under 5 years ${ }^{6}$. Here the lifetime risk of acquiring HBV is between $20-60 \%$. Studies have shown that HBV is responsible for $31.25 \%$ cases of acute hepatitis, $76.3 \%$ cases of chronic hepatitis, $61.15 \%$ cases of cirrhosis of liver and
$33.3 \%$ cases of hepatocellular carcinoma (HCC) in Bangladesh ${ }^{7}$.

Hepatitis B is a vaccine preventable disease for which a safe, immunogenic and effective vaccine is recommended since 1982 though its implementation is still insufficient. ${ }^{7}$ Bangladesh introduced hepatitis $B$ vaccine in a phased manner during 2003-2005 into the routine childhood vaccination schedule provided at 6,10 , and 14 weeks of age. The objective of introducing the vaccine in Bangladesh was to reduce hepatitis B disease burden by $80 \%$. However, the widely recommended hepatitis $B$ vaccine birth dose is not administered in the childhood vaccination schedule in Bangladesh, where $71 \%$ of births occur at home ${ }^{6}$. Vaccines for adults are also available through both government and non-government health services.

Health care personnel are at increased risk of contracting blood borne pathogens due to their occupational exposure to blood and body fluids. When compared to other health personnel, the nursing staff is the group that is most frequently victimized by accidents with cutting and piercing objects, since these professionals are also the ones who most often handle such material while performing their tasks. Thus their chance of accidental exposure to hepatitis $\mathrm{B}$ is high and they are considered as high risk group. Particularly nursing students are at a greater risk due to their limited clinical experience. Knowledge and practice of nursing students and all nurses about transmission of hepatitis B virus, incubation period, high risk groups, signs and symptoms of HBV and vaccination can limit the spread of $H B V$ in a large scale. If proper preventive measures are not followed it may accidentally cause rapid spread of hepatitis B virus. Furthermore, not all hepatitis B infections are symptomatic, meaning a person may spread hepatitis virus without knowing it. Knowledge and Practice of the health care workers plays a key role in prevention of spread of infection. Thus this study was conducted with the objective to assess knowledge and practices of nurses regarding hepatitis B in Dhaka Medical College Hospital. 


\section{Methods:}

A cross sectional study was conducted at different wards of Dhaka Medical College Hospital during the period from January 2015 to June 2015. The sample size of the study was determined conveniently. The target population was all the nurses (both sexes) working at Dhaka Medical College Hospital which was 617. Among them final sample size was 207 from whom data were collected. Purposive sampling technique was followed for collecting data through face to face interview based on structured questionnaire, which includes all the relevant information. After collection of data, they were edited and processed manually. Then they were checked and verified for any omission, error or irrelevance. All data were analyzed by computer. Results obtained were presented in tables, graphs and charts. Simple statistical analysis was done and presented with the result whenever necessary and possible.

\section{Results:}

A total number of 207 respondents participated in the observation. Among them majority $(54.1 \%)$ were aged between 41 to 50 years with a mean age of $33 \pm 0.2$ years. Among them female $(83.5 \%)$ outnumbered the male .Most $(81.2 \%)$ of them were followers of Islam. Some $(15.5 \%)$ were followers of Hinduism. Only 3.4\% of respondents were Christians. About half (49.8\%) had HSC or equivalent educational status. Only $7(3.4 \%)$ respondents had masters or equivalent educational level. Majority $(45.4 \%)$ had a monthly family income greater than 20,000 Taka. Among the respondents more than half $(51.7 \%)$ were married and $45.9 \%$ were unmarried. Most of them (91.8\%) stated that hepatitis B was caused by a virus, $5.3 \%$ stated that it was bacterial origin and $2.9 \%$ replied that it was caused by a parasite. Most of the respondents (84.5\%) stated that hepatitis B mainly transmitted through infected blood transfusion. Others (15.4\%) had misconception about the main route. Among 207 respondents, $172(83.1 \%)$ stated that hepatitis B can be transmitted through other routes, while others 35 (16.9\%) didn't know if any other routes existed. More than half $(52.9 \%)$ stated that it cannot be transmitted through saliva. Majority (59.3\%) stated that hepatitis B can be transmitted through unsafe sex but $40.7 \%$ did not know whether unsafe sex transmitted hepatitis B or not. About $85.5 \%$ knew that this disease can be transmitted vertically from mother to offspring. and $86.0 \%$ stated that hepatitis B can be transmitted through same razors and tattooing needles etc. but $7.6 \%$ stated that it could not be transmitted in such manners and $6.4 \%$ did not know whether hepatitis B could be transmitted in such manner or not. Most of the respondents (96.5\%) knew that this disease could be transmitted through needle sharing, while $3.5 \%$ were unaware about this.

Table -I depicted the knowledge about hepatitis B transmission through frequent blood transfusion. Among all respondents, majority $(64.3 \%)$ were not aware of being at risk of infected by hepatitis B . Only $35.7 \%$ respondents were aware of risk of being infected by hepatitis B. Out of 207 respondents, 176(85\%) stated that hepatitis B had complications, while $2.9 \%$ opined no complications and $12.1 \%$ did not know whether there was any complications or not. In Table - 2 among 176 respondents who stated that hepatitis B had complications, $11(6 \%)$ mentioned Acute hepatitis, 18(10\%) mentioned Chronic hepatitis, 49 (28\%) mentioned Liver cirrhosis, 24(14\%) mentioned Liver cancer and $74(42 \%)$ mentioned all of them. Table -3 showed vaccination status among the respondents. Among 207 respondents, majority (59.4\%) had done blood test for HBV where as $40.6 \%$ had not done the test but most of them (92.8\%) used sterilized surgical instruments, gloves and gowns (88.9\%). Rest $7.2 \%$ did not use sterilized surgical instruments and $11.1 \%$ did not use sterilized gloves and gowns. Most of them (89.9\%) practices recapping syringe after use, only $10.1 \%$ did not recap syringe after use. Again most of them (90.8\%) check HBV by screening before blood transfusion but $9.2 \%$ did not check HBV by screening before blood transfusion. Mean knowledge score was $8.28 \pm 2.9$. Among 207 respondents 40(19.3\%) scored below 6 and were categorized as having poor knowledge while $167(80.7 \%)$ respondents scored 6 or above 
and were categorized as having good knowledge. Table - 4 showed the distribution of the respondents according to practice score. In this study level of preventive practice was significantly associated with level of knowledge $(\mathrm{P}<0.001)$, where 154(92.2\%) respondents who had good knowledge had also good preventive practice.

\section{Table-I}

Distribution of the respondents by their knowledge about transmission of hepatitis $B$ through frequent blood transfusion, $n=172$

Knowledge about hepatitis

B transmission through Frequency Percentage frequent blood transfusion

\begin{tabular}{lcc}
\hline Yes & 144 & 83.7 \\
No & 11 & 6.4 \\
Don't know & 17 & 9.9 \\
\hline Total & 172 & 100.0 \\
\hline
\end{tabular}

Table-II

Distribution of the respondents by their knowledge about diseases as complication of hepatitis $B, n=176$

\begin{tabular}{lcc}
\hline $\begin{array}{l}\text { Knowledge about } \\
\text { Complications of }\end{array}$ & Frequency & Percentages \\
HBV & & \\
\hline Acute Hepatitis & 11 & 6 \\
Chronic Hepatitis & 18 & 10 \\
Liver cirrhosis & 49 & 28 \\
Liver cancer & 24 & 14 \\
All & 74 & 42 \\
\hline Total & 176 & 100 \\
\hline
\end{tabular}

Table-III

Distribution of respondents who received vaccination against $H B V$

$\overline{\text { Received vaccination Frequency Percentage }}$ against hepatitis B

\begin{tabular}{lcc}
\hline Yes & 117 & 56.5 \\
No & 90 & 43.5 \\
\hline Total & 207 & 100.0 \\
\hline
\end{tabular}

Table-IV

Distribution of the respondents according to practice score

\begin{tabular}{lcccc}
\hline $\begin{array}{l}\text { Level of } \\
\begin{array}{l}\text { Preventive } \\
\text { Practice }\end{array}\end{array}$ & $\begin{array}{c}\text { Practice } \\
\text { score }\end{array}$ & & & \\
\hline Poor practice & 0 & 5 & 2.4 & 26 \\
& 1 & 1 & 0.5 & $(12.6 \%)$ \\
& 2 & 6 & 2.9 & \\
& 3 & 14 & 6.8 & \\
Good practice & 4 & 50 & 24.2 & 181 \\
& 5 & 51 & 24.6 & $(87.4 \%)$ \\
& 6 & 80 & 38.6 & \\
\hline & Total & 207 & 100.0 & \\
\hline
\end{tabular}

\section{Discussion}

The study sought to evaluate knowledge \& preventive practice towards HBV among the nurses in Dhaka Medical College Hospital. Results of the study showed satisfactory knowledge \& preventive practice towards HB. The mean knowledge score was $8.28 \pm 2.9$, where $80.7 \%$ respondents categorized as having good knowledge. Again mean preventive practice score was $4.78 \pm 1.3$, where $87.4 \%$ respondents categorized as having good practice. In this study mean practice of prevention of the respondents was significantly associated with their level of knowledge $(\mathrm{P}<0.001)$. These results are in line with the findings from studies reported from some selected public \& private hospitals of Dhaka city, Bangladesh, where majority (67.3\%) of the nurses had adequate level of knowledge on HB \& 49.3\% had good level of preventive practice. They found significant association between level of knowledge and level of preventive practice $(\mathrm{P}<0.05)^{9}$. Similarly in Bolan Medical Complex Hospital, Quetta, Pakistan 11, about 90.7\% nurses had acceptable knowledge about HBV infection and vaccine. A dissimilar finding was given in the study among healthy population done in Quetta, Pakistan 9, where the respondents demonstrated a very low knowledge of hepatitis B infection and also in Ethiopia $\mathbf{1 2}$ similar picture that is, poor knowledge and practice towards HB was found among medical $\&$ health science students. In 
Nigeria ${ }^{13} 65.2 \%$ had good knowledge but only $37.6 \%$ put the measures into practice.

Present study showed that majority (49.8\%) was educated up to H.S.C. or equivalent level. Again $45.4 \%$ had monthly income $>20,000$ BDT which can contribute satisfactory practice. More or less similar age group\& educational level was found in the study done by Haq NU et. al ${ }^{11}$, Mesfin YM, Kibret KT(2013) ${ }^{12}$, Singh A \& Jain $\mathrm{S}(2010){ }^{14}$ and Mengal HR et. al ${ }^{10}$ respectively. Other studies done in Kathmandu, Nepal ${ }^{15}$,Ibahan, Nigeria, ${ }^{13}$ had a different picture regarding age, sex, religion, educational status, marital status and monthly family income.

In our study $91.8 \%$ responded that virus is a cause of hepatitis B. This is supported by an institutional based study in Kathmandu, Nepal 15 where $92.2 \%$ had the good understanding about causative agent as a virus. Two other studies done in Bangladesh by Mehrabin $\mathrm{N}$ et. $\mathrm{al}^{9}$ and in Ahmedabad, India done by Singh A \& Jain $\mathrm{S}^{14}$ also found the correct answer among $92.7 \% \quad \& \quad 86.7 \%$ respondents respectively.

In this study most $(84.5 \%)$ of the respondents understood that infected blood transfusion is the common means of mode of transmission of hepatitis B. Three other studies are also consistent with our study. First study done in Kathmandu, Nepal ${ }^{15}$ found $97.7 \%$ nursing students, secondly $98 \%$ were found among nurses in a study conducted in Dhaka city, Bangladesh ${ }^{9} \&$ in Ahmedabad, India ${ }^{14}$, found $87 \%$ respondents who knew infected blood transfusion as the common mode of transmission of HB. Another study conducted in Bangladesh by Rahman MA \& Mannan SR 16 found a different picture, where $73 \%$ did not know that blood products are responsible for $\mathrm{HBV}$, it may be that the respondents are all female of different community \& mostly of low educational level.

Among 207 study participants $172(83.1 \%)$ had the knowledge about other routes of transmission of hepatitis B. Out of them 48 $(27.9 \%)$ gave affirmative answer for transmission through saliva, 59.3\% opined unsafe sex, $85.5 \%$ had knowledge about vertical transmission from mother to offspring, $86.0 \%$ knew about sharing and reuse of sharp instrument. These results are in line with the findings from studies reported from Kathmandu, Nepal ${ }^{15}$, where $97.4 \%$ reported "infected blood receivers" are the high risk groups. Again in Dhaka, Bangladesh ${ }^{9}$ they reported unsafe sex $88 \%$, needle sharing \& using same razor $98.4 \%$ , piercing / tattooing $86 \% \& \mathrm{I} / \mathrm{V}$ drug abusers $88.3 \%$. Also report from BJ Medical College Ahmedabad \& Gujarat, India ${ }^{14}$ where majority of the medical students had correct knowledge on mode of transmission. On the other hand, a KAP study conducted by Rahman MA \& Mannan $\mathrm{SR}^{16}$ in Dhaka, Bangladesh found that $50 \%$ of married women of reproductive age group had misconceptions regarding mode of transmission of HBV and also in North India 17 among $2501^{\text {st }}$ year students of medical, dental $\&$ nursing colleges had poor knowledge (12\%) about vertical transmission. Unsafe blood transfusion as a risk factor of HBV was known by $35.2 \%$. About one fifth and one tenth of the respondents considered reused needles \& unsafe sex as risk factors for HBV respectively.

In the present study, majority (51.7\%) were not aware of being at risk of infected by hepatitis B but they had the knowledge (85\%) about complications. They stated that liver cirrhosis (23.4\%) was more common complication of HB. Other complications like, liver cancer (11.3\%), chronic hepatitis $(8.6 \%)$ and acute hepatitis (5.3\%)were also mentioned. More than half $(51.2 \%)$ mentioned all of them. These findings are similar to other studies done among nursing students of Kathmandu, Nepal, 15 where majority $(85.7 \%)$ perceived "Liver damage" as a major complication. Mehrabin N et.al. ${ }^{9}$ also found that $91.7 \%$ knew about hepatocellular carcinoma/ cirrhosis.

Regarding vaccination status majority (56.5\%) received vaccination against $\mathrm{HBV}$. More or less similar studies were found among nurses of different public \& private hospitals of Dhaka city, Bangladesh, 9 where 59\% reported vaccinated and also $65.7 \%$ reported vaccinated in a multicenter study among health care workers in Ibahan, Nigeria ${ }^{13}$. In Ahmedabad, 
India study among medical students reported that only $29.3 \%$ were not vaccinated against HBV \& also among nursing students of Bolan Medical Complex Hospital, Quetta, Pakistan 10 reported $25 \%$ had not been vaccinated at all. In our study among nurses $43.5 \%$ were not vaccinated. This indicates that the study populations are not aware of HBV. Again among general population like married women in reproductive age group done in Dhaka city, Bangladesh 16 reported only 4\% women were fully immunized against HBV. Very poor vaccination status was also found at Haramaya University, Ethiopia ${ }^{12}$. These studies are very alarming \& measures should be taken quickly both from concerned government as well as from society.

The present study shows that more than half $(59 \%)$ had done blood test for HBV. This practice is not matched with the respondents of the study done by Haq NU, Hassali MA, et.al. ${ }^{11}$ in Quetta, Pakistan where 96.9\% never went for HB screening . In the study done in Haramaya University, Ethiopia, 12 similar picture was found where $85.7 \%$ never screened for HB. Study conducted by Mehrabin N, Ahsan GU, Islam $\mathrm{T}^{9}$ among nurses in Dhaka city, Bangladesh is consistent with our study where $69 \%$ respondents tested blood for hepatitis B. This is surely a good practice.

Present study revealed some good preventive practices among respondents against HBV .Of them $92.8 \%$ use sterilized surgical instruments, $88.9 \%$ use sterilized gloves $\&$ gowns, $89.9 \%$ recap syringe after use, $90.8 \%$ screen for HBV before blood transfusion. These results are in line with the findings from studies reported from different hospitals in Dhaka city, Bangladesh ${ }^{9}$ among nurses, where 92.7\% used sterilized instruments, $46.3 \%$ used gowns. More or less similar preventive practices were found among health care workers in Ibahan, Nigeria ${ }^{13} \&$ also among nursing students of Bolan Medical Complex Hospital, Quetta, Pakistan 10, where $80.4 \%$ used disposable gloves. But poor practice was found among medical students who were starting clinical attachment in Haramaya University, Ethiopia, ${ }^{12}$ where $31.7 \%$ never asked for screening of blood before transfusion, $16.5 \%$ never asked for a new syringe.

The positive correlations between knowledge and practice in this study reaffirm the relationship between knowledge $\&$ practice with infection control measures. It is concluded that adequate knowledge can lead to good practices.

\section{Conclusion}

In the light of present study the existing level of knowledge and preventive practice is satisfactory among the nurses in Dhaka Medical College Hospital. Most of them has good knowledge about causative agent of HBV and its mode of transmission. Majority receive vaccination for $\mathrm{HBV}$ and they know the complications of HBV. But nearly half of the respondents are not aware of risk among themselves by hepatitis B. It may be due to lack of participation in health education program regarding hepatitis $B$. Nursing staffs are the first level of contact between patients and medical care and always exposed to blood and blood products in their professional practice. By all means, we should make sure the nursing staff is kept up-to-date and very well educated, starting from their formal educations at the nursing college

\section{References}

1. Park K; Park's text book of prevention \& social medicine, 15 th edition. India MS Bannasidas Bhanot , 1997 ;157-159

2. Massachusetts Department of Public Health, Bureau of Communicable Disease Control; Guide to Surveillance, Reporting and Control [Internet]; 1 st ed. 2006. Available from: http:// www.mass.gov/eohhs/docs/dph/diseasereporting/ guide/hepatitis-b.pdf

3. WHO; Hepatitis: fact sheets [Internet]. 2015. Available from: http://www.who.int/topics/ hepatitis / factsheets/en/

4. Franco E; Hepatitis B: Epidemiology and prevention in developing countries; World Journal of Hepatology. 2012; 4(3):74.

5. WHO; Hepatitis B [Internet]. 2015. Available from: http://www.who.int/csr / disease/ hepatitis / whocdscsrlyo20022/en/

6. iccdr,b; Impact of Hepatitis B vaccination programme in Bangladesh; Health and Science Bulletin. 2013; 11(1):1-8. 
7. Al-Mahtab M, Rahman S, Karim M; Guideline for treating hepatitis B virus infection in Bangladesh; Bangladesh Liver Journal. 2009; 1(1).

8. Centers for Disease Control and Prevention. Case Definitions for Infectious Conditions Under Public Health Surveillance. MMWR. 1997; 46(RR-10)

9. Mehrabin N, Ahsan G, Islam T; Knowledge and preventive practices regarding Hepatitis B among nurses in some selected hospitals of Dhaka city, Bangladesh; SE Asia J Pub Health. 2015; 4(1).

10. Mengal A et al ; Factors Relating to Acceptance of Hepatitis B Virus Vaccination by Nursing Students in a Tertiary Hospital, Pakistan; J Health Popul. Nutr. March 2008; 26(1) : 46-53.

11. Haq N, Hassali M, Shafie A, Saleem F, Farooqui $\mathrm{M}$, Aljadhey $\mathrm{H}$; A Cross Sectional Assessment of knowledge, attitude and practice towards Hepatitis B among healthy population of Quetta, Pakistan; BMC Public Health. 2012; 12(1):692.

12. Mesfin Y, Kibret K; Assessment of Knowledge and Practice towards Hepatitis B among Medical and Health Science Students in Haramaya University, Ethiopia; PLoS ONE. 2013; 8(11):e79642.
13. Oyewusi CO, Okanlawon FA, Ndikom CM; Knowledge and Utilization of HepatitisB Infection Preventive Measures and Influencing Factors among Health Care Workers in Ibahan, Nigeria; International Journal of Caring Sciences. JanuaryApril 2015; 8(1):164-176.

14. Singh A, Jain S; Prevention of Hepatitis BKnowledge and Practices among Medical Students; Indian Medical Gazette. February 2015; 52-56.

15. Paudel D, Prajapati S, Paneru D; Preventive practices against Hepatitis B: A cross-sectional study among nursing students of Kathmandu, Nepal; Journal of the Scientific Society. 2012; 39(3): 109.

16. Rahman MA, Mannan SR; The Knowledge Attitude and Practices Regarding HBV Infection of Married Women in the Reproductive Age group living in Different Districts of Bangladesh; Medicine Today. 2010; 22(1):1-3.

17. Maroof KA, Bansal R; Do the medical, dental, nursing students of first year know about hepatitis B? A study from a university of North India; J Pak Med Assoc. January 2012; 62(1):25-7. 